\title{
COMPATIBILITY ANALYSIS OF SERUM ASCITES ALBUMIN GRADIENT AND ASCITIC FLUID EVALUATION TO CLINICAL DIAGNOSIS OF PATIENT
}

\author{
Ivonne Desiana ${ }^{1}$, Yuyun Widaningsih ${ }^{2}$, Fitriani Mangarengi ${ }^{3}$ \\ Specialization Program of Clinical Pathology, Faculty of Medicine, Hasanuddin University/Dr. Wahidin Sudirohusodo Hospital, Makassar, \\ Indonesia. E-mail: ivonnedesiana@yahoo.co.id \\ Department of Clinical Pathology, Faculty of Medicine, Hasanuddin University/Hasanuddin University Hospital, Makassar, Indonesia \\ ${ }^{3}$ Department of Clinical Pathology, Faculty of Medicine, Hasanuddin University/Syekh Yusuf Hospital, Gowa, Indonesia
}

\section{ABSTRACT}

Ascites is a condition of abnormal fluid accumulation in the peritoneal cavity that can be caused by many underlying diseases. Several studies concluded that ascitic fluid analysis with the transudate-exudate concept has been replaced by a greater indicator known as Serum Ascites Albumin Gradient (SAAG). This study aimed to analyze the compatibility of SAAG and ascitic fluid evaluation to the clinical diagnosis of patients in Dr. Wahidin Sudirohusodo Hospital Makassar. The retrospective cross-sectional study was conducted by taking data from all patients with ascites condition and examining both ascitic fluid and serum albumin simultaneously or within 3 days at the Dr. Wahidin Sudirohusodo Hospital Makassar from January - August 2018. Statistical analysis was performed to determine frequency distribution and Kappa statistical tests to analyze the compatibility of SAAG and ascitic fluid evaluation for clinical diagnosis of the patient. A total of 68 subjects were included in this study and it was found that both ascitic fluid examination and SAAG were significantly compatible to the clinical diagnosis with $25.8 \%(p<0.05), 42.5 \%(p<0.001)$, respectively. SAAG and ascitic fluid evaluation were significantly in accordance with the clinical diagnosis of the patient. The compatibility value of SAAG was greater than ascitic fluid evaluation. Therefore, SAAG is more recommended for ascites examination.

Key words: SAAG, ascitic fluid evaluation, transudate-exudate, clinical diagnosis

\section{INTRODUCTION}

Ascites is a condition of abnormal fluid accumulation in the peritoneal cavity. ${ }^{1,2}$ Normal fluid volume in the peritoneal cavity is $1-10 \mathrm{~mL}$ which covers the surface of tunica serosa. ${ }^{1}$ Many diseases and conditions can cause ascites, one of which is liver cirrhosis with portal hypertension as the most common cause of transudative ascites and malignancy as the most common cause of exudative ascites. ${ }^{2}$ Ascitic fluid evaluation is performed to differentiate the type of fluid (transudate and exudate) to help diagnose the underlying diseases of ascites. $^{3}$

Several studies about the accuracy of ascitic fluid evaluation had been carried out and the results concluded that the transudates-exudates concept of ascitic fluid evaluation have been replaced with greater indicator, namely Serum Ascites Albumin Gradient (SAAG) which was first introduced by Hoefs et al. in 1981, to assist in the diagnosis of the underlying condition of ascites. ${ }^{2-6}$

Serum Ascites Albumin Gradient classifies the conditions related to ascites into two groups, conditions related to portal hypertension and conditions not related to portal hypertension. The gradient was calculated by subtracting the ascites albumin concentration from the serum albumin concentration. The cut-off for SAAG is $1.1 \mathrm{gr} / \mathrm{dL}$. High Gradient (SAAG $\geq 1.1 \mathrm{gr} / \mathrm{dL}$ ) shows that the cause of ascites is related to portal hypertension such as hepatic cirrhosis, congestive heart disease, Budd-Chiari syndrome, and portal vein thrombosis. Low Gradient (SAAG < $1.1 \mathrm{gr} / \mathrm{dL}$ ) shows that the cause of ascites is related to conditions other than portal hypertension, such as malignancy, abdominal tuberculosis, nephrotic syndrome, pancreatitis, vasculitis, etc. $^{6}$

Younas et.al compared the SAAG formula and the Ascitic Fluid Total Protein (AFTP) test with clinical diagnosis in 93 patients at the Armed Forces Institute of Pathology, Rawalpindi. The cut-off used for the AFTP test was $2.5 \mathrm{gr} / \mathrm{dL}$ ( $\geq 2.5 \mathrm{gr} / \mathrm{dL}$ for exudate and $<2.5 \mathrm{gr} / \mathrm{dL}$ for transudate). Sensitivity and specificity for SAAG were higher than those of AFTP, compared to the clinical diagnosis of patients. The sensitivity 
and specificity of SAAG were $97 \%$ and $95 \%$ respectively, while the sensitivity and specificity of the AFTP test were only $53 \%$ and $70 \%$ respectively.

Uddin et.al studied the diagnostic accuracy of SAAG and confirmed SAAG as new diagnostic criteria for differentiating ascitic fluid. This study was conducted on 50 patients with ascites at Comilla Medical College Hospital from July 2010 to June 2011. Venous blood sampling and ascitic fluid paracentesis were performed simultaneously in patients. The accuracy of SAAG formula compared to clinical diagnosis was $97 \%$, while the accuracy of ascitic fluid evaluation using transudate-exudate concept was $83 \%$.

Based on research conducted by Younas and Uddin, researchers were interested in conducting a similar study about compatibility analysis of SAAG and ascitic fluid evaluation to clinical diagnosis of patients at the Dr. Wahidin Sudirohusodo Hospital Makassar. The result was expected to help clinicians choose a better and more efficient ascitic fluid analysis to determine the underlying clinical condition of ascites then can indirectly improve the quality of hospital services.

\section{METHODS}

The design of this study was retrospective cross-sectional by taking secondary data from the medical records of patients who were hospitalized at the Dr. Wahidin Sudirohusodo Hospital Makassar from January to August 2018. The study was conducted at the Clinical Pathology Laboratory and Medical Record Installation at the Dr. Wahidin Sudirohusodo Hospital Makassar starting from August to September 2018.

The population of this study was all patients with ascites who were registered at the Dr. Wahidin Sudirohusodo Hospital Makassar. Samples were all patients who met the inclusion criteria who simultaneously underwent both ascitic fluid and serum albumin analysis within 3 days at the Dr. Wahidin Sudirohusodo Hospital Makassar from January-August 2018. Exclusion criteria of this study were all patients with no complete medical record data, patients who received albumin therapy and patients with unknown diagnosis or not related to ascites.

This study used total protein level as the evaluation criteria of ascites fluid, with $2.5 \mathrm{gr} / \mathrm{dL}$ as a cut-off of total protein measurement ( $\geq 2.5 \mathrm{gr} / \mathrm{dL}$ for exudate and $<2.5 \mathrm{gr} / \mathrm{dL}$ for transudate). The cut-off used for SAAG was $1.1 \mathrm{gr} / \mathrm{dL}$. (High Gradient if SAAG $\geq 1.1 \mathrm{gr} / \mathrm{dL}$; Low Gradient if SAAG $<1.1 \mathrm{gr} / \mathrm{dL}$ ).
Data were analyzed using SPSS version 22. Statistical analysis such as the calculation of frequency distribution and Kappa statistical test was performed to determine the compatibility of SAAG and ascitic fluid evaluation to clinical diagnosis of patients. A significance level of 0.05 was used.

Ethical clearance was obtained from the Health Research Ethics Commission, Faculty of Medicine, Hasanuddin University/Dr. Wahidin Sudirohusodo Hospital Makassar with number: 572/H4.8.4.5.31/ PP36-KOMETIK/2018.

\section{RESULTS AND DISCUSSION}

The study was conducted on 68 subjects with the following characteristics (Table 1 ).

Most of the subjects were males (67.6\%) and aged over 50 years (47.1\%). The most clinical diagnosis found was hepatic cirrhosis (45.5\%). Ascitic fluid classification based on clinical diagnosis showed that the majority was transudate group (75.0\%), similar to the results of ascitic fluid evaluation showing the transudate group (58.8\%) as well. The SAAG classification based on clinical diagnosis showed $60.3 \%$ of high gradient group, similar to the SAAG laboratory test result (69.1\%).

There was significant compatibility of ascitic fluid evaluation to the clinical diagnosis of the patient $(p<0.05)$. From 17 subjects with exudate ascitic fluid based on clinical diagnosis, 11 subjects (64.7\%) were similarly evaluated as exudate ascitic fluid. Meanwhile, from 51 subjects with transudate ascitic fluid based on clinical diagnosis, transudate ascitic fluid was found in 34 subjects (66.7\%). According to the value from the Kappa test, the statistical compatibility value of ascitic fluid evaluation to clinical diagnosis of patient was 0.258 (25.8\%) (Table 2 and Figure 1 ).

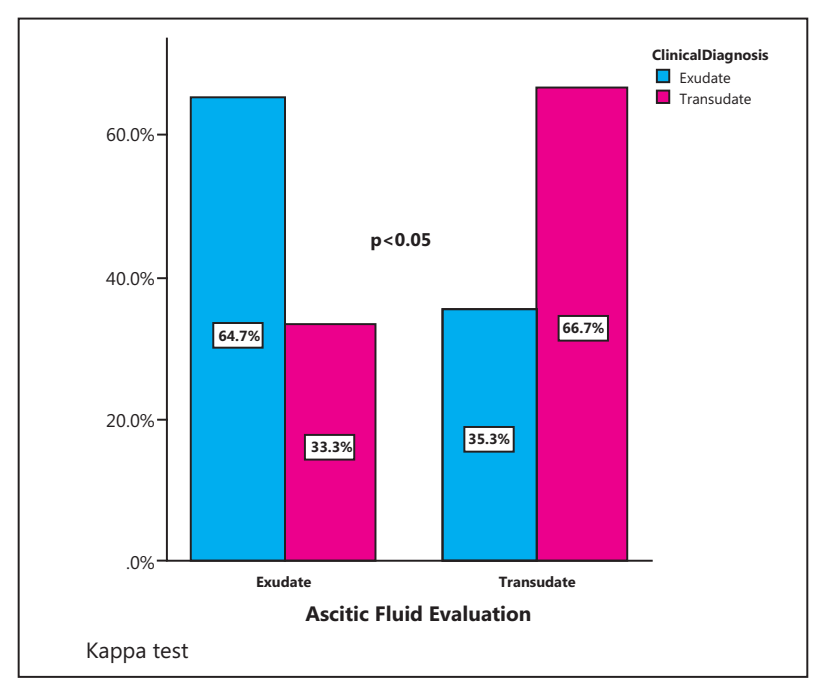

Figure 1. Compatibility of ascitic fluid evaluation to clinical diagnosis of the patient 
Table 1. Characteristics of the subjects

\begin{tabular}{|c|c|c|c|}
\hline \multicolumn{2}{|l|}{ Variables } & \multirow{2}{*}{$\frac{\mathbf{n}=\mathbf{6 8}}{46}$} & \multirow{2}{*}{$\frac{\%}{67.6}$} \\
\hline & Male & & \\
\hline sex & Female & 22 & 32.4 \\
\hline \multirow{4}{*}{ Age (years) } & $<40$ & 15 & 22.1 \\
\hline & $40-49$ & 21 & 30.9 \\
\hline & $50-59$ & 15 & 22.1 \\
\hline & $>=60$ & 17 & 25.0 \\
\hline \multirow{10}{*}{ Clinical diagnosis } & Hepatic cirrhosis & 31 & 45.5 \\
\hline & Malignancy & 12 & 17.6 \\
\hline & Hepatoma & 9 & 13.2 \\
\hline & Chronic kidney disease & 8 & 11.7 \\
\hline & Bacterial peritonitis & 2 & 3.0 \\
\hline & Liver abscess & 2 & 3.0 \\
\hline & Congestive heart disease & 1 & 1.5 \\
\hline & Malnutrition & 1 & 1.5 \\
\hline & Nephrotic syndrome & 1 & 1.5 \\
\hline & Pulmonary tuberculosis & 1 & 1.5 \\
\hline \multirow{2}{*}{$\begin{array}{l}\text { Ascitic fluid based on clinical } \\
\text { diagnosis }\end{array}$} & Transudate & 51 & 75.0 \\
\hline & Exudate & 17 & 25.0 \\
\hline \multirow{2}{*}{ Ascitic fluid evaluation } & Transudate & 40 & 58.8 \\
\hline & Exudate & 28 & 41.2 \\
\hline \multirow{2}{*}{ SAAG based on clinical diagnosis } & Low gradient & 27 & 39.7 \\
\hline & High gradient & 41 & 60.3 \\
\hline \multirow{2}{*}{ SAAG laboratory } & Low gradient & 21 & 30.9 \\
\hline & High gradient & 47 & 69.1 \\
\hline
\end{tabular}

Resource: Secondary data

Table 2. Compatibility of ascitic fluid evaluation to clinical diagnosis of the patient

\begin{tabular}{|c|c|c|c|c|}
\hline \multirow[b]{2}{*}{ Clinical Diagnosis } & & \multicolumn{2}{|c|}{ Ascitic Fluid Evaluation } & \multirow[b]{2}{*}{ Total } \\
\hline & & Exudate & Transudate & \\
\hline \multirow{2}{*}{ Exudate } & $n$ & 11 & 6 & 17 \\
\hline & $\%$ & $64.7 \%$ & $35.3 \%$ & $100.0 \%$ \\
\hline \multirow{2}{*}{ Transudate } & $\mathrm{n}$ & 17 & 34 & 51 \\
\hline & $\%$ & $33.3 \%$ & $66.7 \%$ & $100.0 \%$ \\
\hline \multirow{2}{*}{ Total } & $\mathrm{n}$ & 28 & 40 & 68 \\
\hline & $\%$ & $41.2 \%$ & $58.8 \%$ & $100.0 \%$ \\
\hline
\end{tabular}

Kappa test (value $=0.258 p=0.023$ )

Table 3. Compatibility of SAAG to clinical diagnosis of patient

\begin{tabular}{|c|c|c|c|c|}
\hline \multirow[b]{2}{*}{ Clinical Diagnosis } & & \multicolumn{2}{|c|}{ SAAG } & \multirow[b]{2}{*}{ Total } \\
\hline & & $\begin{array}{c}\text { Low } \\
\text { gradient }\end{array}$ & $\begin{array}{c}\text { High } \\
\text { gradient }\end{array}$ & \\
\hline \multirow{2}{*}{ Low gradient } & $\mathrm{n}$ & 15 & 12 & 27 \\
\hline & $\%$ & $55.6 \%$ & $44.4 \%$ & $100.0 \%$ \\
\hline \multirow{2}{*}{ High gradient } & $\mathrm{n}$ & 6 & 35 & 41 \\
\hline & $\%$ & $14.6 \%$ & $85.4 \%$ & $100.0 \%$ \\
\hline \multirow{2}{*}{ Total } & $\mathrm{n}$ & 21 & 47 & 68 \\
\hline & $\%$ & $30.9 \%$ & $69.1 \%$ & $100.0 \%$ \\
\hline
\end{tabular}

Kappa test (value $=0.425, \mathrm{p}=0.000$ ) 
There was very significant compatibility of SAAG laboratory to clinical diagnosis of the patient ( $p$ $<0.001$ ). From 27 subjects with low gradient SAAG group based on clinical diagnosis, low gradient SAAG from laboratory test were similarly found in 15 subjects (55.6\%). Meanwhile, from 41 subjects with high gradient SAAG group based on clinical diagnosis, high gradient SAAG from laboratory test were similarly found in 35 subjects (85.4\%). According to the value from the Kappa test, the statistical compatibility value of SAAG to clinical diagnosis of the patient was 0.425 (42.5\%) (Table 3 and Figure 2).

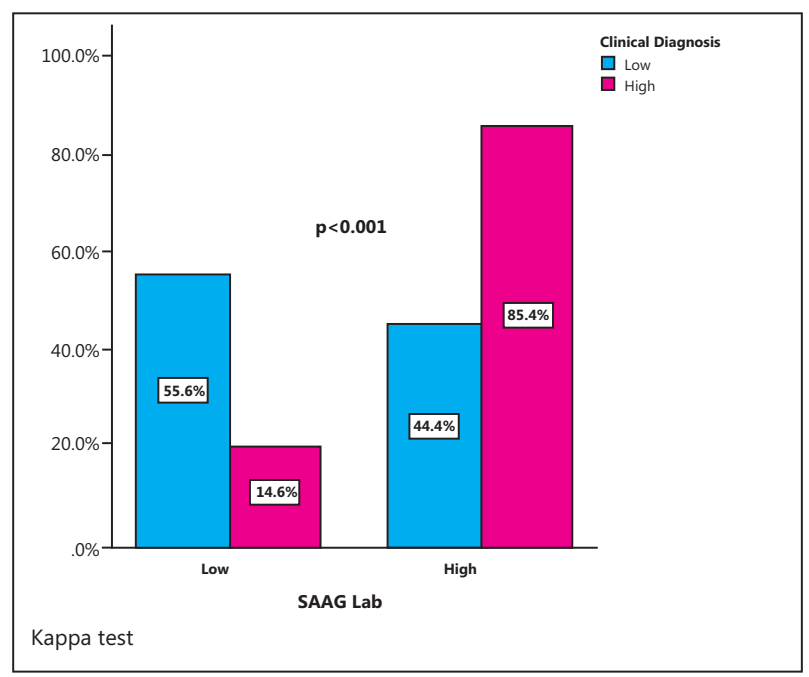

Figure 2. Compatibility of SAAG to Clinical Diagnosis of the Patient

The most common clinical diagnosis found in this study was hepatic cirrhosis. These results were in accordance with the previous data suggesting that the most common cause of ascites was hepatic cirrhosis with portal hypertension (85\%). Therefore, the results of the ascitic fluid evaluation and SAAG test in this study were classified into transudate group (66.7\%) and high gradient SAAG group (85.4\%). ${ }^{2}$

Transudate is caused by an increase in plasma hydrostatic pressure in the capillary arteries and/or a decrease in plasma oncotic pressure in the capillary membrane. While the exudate is caused by an inflammatory process or infection which results in increased capillary blood vessel permeability. The most common cause of exudative ascitic fluid from this study was a malignancy, similar to the results of previous studies. ${ }^{1,2,8}$

Serum ascites albumin gradient is a formula used to help in differentiating ascitic fluid based on the condition of ascites, related to portal hypertension (transudate) and unrelated to portal hypertension (transudate and exudate). The SAAG formula is based on the balance of hydrostatic pressure and vascular oncotic pressure. The SAAG formula is: ${ }^{6}$

SAAG = Serum Albumin - Ascitic Fluid Albumin ( $\mathrm{gr} / \mathrm{dl}$ )

Serum albumin is an albumin level in serum measured by the automatic chemical analyzer. The normal range of serum albumin level is $3.5-5.0 \mathrm{gr} / \mathrm{dL}$. Serum albumin is synthesized in the liver and has 18-20 days of half-life leading to $<4 \%$ of albumin degradation per day. hence this study was permitted using samples with three-day difference between paracentesis and blood collection. ${ }^{9}$

The results of the ascitic fluid evaluation were significantly compatible with the clinical diagnosis of the patient. 45 of 68 subjects showed compatibility of ascitic fluid evaluation with the clinical diagnosis. The incompatibility between the results of the ascites fluid evaluation and the clinical diagnosis was found in 23 subjects, with 17 of them were tested diagnosed with exudate in ascitic fluid evaluation although they were clinically diagnosed with transudate. This was possibly caused by the presence of unknown diseases, for example, the exudate ascites fluid in patients with hepatic cirrhosis (transudate) because of the inflammation or infection leading to the proteins in the blood vessels to migrate to ascitic fluid. ${ }^{6}$

The results of the SAAG test were significantly compatible with the clinical diagnosis of the patient. Compatibility between clinical diagnosis and SAAG test was found in 50 of 68 subjects. This was due to hepatic cirrhosis with portal hypertension as the most common cause of ascites in this study. The incompatibility between the results of SAAG test and the clinical diagnosis was found in 18 subjects, with 12 of them showed high gradient SAAG despite low gradient SAAG results based on the clinical diagnosis. This was possibly caused by an increase in portal venous pressure due to portal venous thrombosis as an acute complication of pancreatic malignancy or pancreatitis. ${ }^{9}$

The compatibility value of SAAG based on clinical diagnosis was statistically greater (45.8\%) than ascitic fluid evaluation with the transudate-exudate concept (25.8\%). This was because SAAG was a more sensitive and specific for diagnosing ascites in patients with portal hypertension and the most clinical diagnosis found in this study was hepatic cirrhosis with portal hypertension. ${ }^{6}$ The result of this 
study were in line with the previous studies suggesting that SAAG showed better accuracy than ascitic fluid evaluation in diagnosing underlying diseases of ascites.

\section{CONCLUSION AND SUGGESTION}

Based on this study, the results of the ascitic fluid evaluation and SAAG fluid were significantly compatible with the clinical diagnosis of the patient. The SAAG compatibility value was greater than the results of the ascitic fluid evaluation. Therefore, SAAG can be recommended as a more accurate and efficient ascitic fluid analysis in diagnosing underlying diseases of ascites.

Researchers suggested further research to analyze the compatibility of another parameter from ascitic fluid evaluation in addition to the total protein level with the clinical diagnosis of the patient.

\section{REFERENCES}

1. Fauci AS, Kasper DL, Hauser SL, Longo DL, Jameson JL, et al. Harrison's manual of medicine. $19^{\text {th }} \mathrm{Ed}$., New York, The McGraw-Hill Companies, 2014; 271-4.

2. Appenrodt B. Ascites, hyponatremia and hepatorenal syndrome: Progress in treatment. Germany, Karger, 2011; 1-10.
3. Strasinger SK, Lorenzo MS. Urinalysis and body fluids. $6^{\text {th }}$ Ed., Philadelphia, F.A. Davis Company, 2014; 237-40.

4. Sanyal AJ, Bajaj JS, Shaw J. Ascites, hyponatremia and hepatorenal syndrome: Progress in treatment. Germany, Karger, 2011; 23-31.

5. Uddin MS, Hogue MI, Islam MB, Mondol G. Serum-ascites albumin gradient in differential diagnosis of ascites. Mymensingh Medical Journal, 2013. https://www.ncbi.nlm.nih.gov/pubmed/ 24292307 (accessed on July 4, 2018).

6. Huang LL, Xiang HH, Zhu SL. Ascitic fluid analysis in the differential diagnosis of ascites. Journal of Clinical and Translational Hepatology, 2015. https://www.ncbi.nlm.nih.gov/pmc/articles/PMC452 1252/ (accessed on July 4, 2018).

7. Younas M, Sattar A, Hashim R, Dilawar M. Role of serum-ascites albumin gradient in differential diagnosis of ascites. Journal of Ayub Medical College, 2012. https://www.ncbi.nlm.nih.gov/ pubmed/24669623 (accessed on July 4, 2018).

8. Brunzel NA. Fundamentals of urine and body fluid analysis. $4^{\text {th }}$ Ed., Missouri, Elsevier, 2018; 264-5.

9. Ghany $\mathrm{M}$, Hoofnagle JH. Approach to the Patient with Liver Disease. In: Longo DN, Fauci AS. $2^{\text {nd }}$ Ed., Harrison's Gastroenterology and Hepatology. New York, McGraw Hill, 2013; 331-45. 